\title{
Distribution Pattern of the Non Polio Enterovirus (NPEV) Rate in Children with Acute Flaccid Paralysis Reported to the Surveillance System in Nigeria 2010-2015
}

\author{
Bassey Enya Bassey*, Braka Fiona, Ticha Johnson Muluh, Komakech William, \\ Maleghemi Sylvester Toritseju, Ajiboye Oyetunji, Akpan Godwin Ubong, Angela Okocha-Ejeko \\ Nigeria Country Office, World Health Organization (WHO), Garki, Abuja \\ Email: ‘bassey69@yahoo.com, brakaf@who.int, tichaj@who.int, komakechw@who.int, maleghemis@who.int, ajiboyet@who.int, \\ akpang@who.int, peaches_spears@rocketmail.com
}

How to cite this paper: Bassey, B.E., Fiona, B., Muluh, T.J., William, K., Toritseju, M.S., Oyetunji, A., Ubong, A.G. and Okocha-Ejeko, A. (2018) Distribution Pattern of the Non Polio Enterovirus (NPEV) Rate in Children with Acute Flaccid Paralysis Reported to the Surveillance System in Nigeria 2010-2015. Health, 10, 907-918. https://doi.org/10.4236/health.2018.107067

Received: March 21, 2018

Accepted: July 3, 2018

Published: July 6, 2018

Copyright $\odot 2018$ by authors and Scientific Research Publishing Inc. This work is licensed under the Creative Commons Attribution-NonCommercial International License (CC BY-NC 4.0). http://creativecommons.org/licenses/by-nc/4.0/ (c) (i) \& Open Access

\begin{abstract}
Objective: This study focuses on the reverse cold chain system of stool sample management from cases reported to the AFP surveillance system between 2010 and 2015. Through the distribution of their NPEV isolation rates, we identify lapses in the reverse cold chain management and provide recommendations that should help improve the reverse cold chain system and the AFP surveillance system in general as Nigeria once again matches towards a polio free certification. Methods: A descriptive retrospective study was conducted using AFP surveillance data routinely collected between January 2010 and December 2015 by the Disease Surveillance and Notification Officers (DSNOs) in Nigeria and the WHO accredited Polio Laboratories. All AFP cases reported to the Disease Surveillance network during this period from all the states were included in the study. EPIINFO-veritable customized software was used to run queries on the access database and obtain the specific data sets required. Results: A total of 52,879 AFP cases were reported from 2010-2015, in which 7288 non-polio enteroviruses were isolated. NPEV isolation rate ranged from $10.8 \%$ in the southeast to $20.3 \%$ in the northeast with the states in the northern geopolitical zones having higher NPEV rates in comparison to the states in the southern geopolitical zones. The WHO Polio laboratory in Ibadan serves twenty-seven states in the country; the average non-polio AFP rate among states served by this laboratory is $11.7 \%$ from a total of 4012 AFP cases recorded. The WHO Polio laboratory in Maiduguri recorded 3276 with an average non-polio AFP rate of 19.2\%. Conclusion: Though the country's NPEV isolation rate remain slightly higher above the
\end{abstract}


$10 \%$ recommended by WHO, steps should be taken to enhance the reverse cold-chain system particularly in the southern states. This would increase confidence in the AFP surveillance system in Nigeria as she proceeds once again towards complete polio eradication and meeting certification standards.

\section{Keywords}

Non-Polio-Enterovirus-Rate, Acute-Flaccid-Paralysis, Surveillance, Nigeria

\section{Introduction}

With the attainment of a polio-free certification by four of the six World Health Organization (WHO) regions, it is safe to say that the quest for a worldwide eradication of poliomyelitis, which began in 1988 with the inauguration of the Global Polio Eradication Initiative (GPEI) by the World Health Assembly (WHA) is almost complete [1] [2]. So far, Nigeria remains the only country in the African region without a polio free certification [2].

An active Acute Flaccid Paralysis (AFP) surveillance system remains the gold standard for the polio eradication initiative. Poliovirus surveillance involves a systematic isolation of the virus from stool samples of AFP cases. An AFP surveillance system must be sensitive enough to pick at least 3 cases per 100,000 children below the age of 15 years [3]. For all cases reported, 2 stool samples are collected at least 24 hours apart within 14 days of paralysis onset. The specimen is then transported to a WHO accredited laboratory via a reverse cold-chain transport system for polio enterovirus isolation [4].

Fortunately, these viral isolation procedures also detect non-polio enteroviruses (NPEV), either because these are the aetiology of flaccid paralysis in some cases or, if not related to flaccid paralysis, because they are shed with stool as innocent bystanders [5] [6]. NPEV exists worldwide and numerous outbreaks have been recorded. According to the guidebook issued by the WHO, just less than $1 \%$ of the patients who were infected with NPEV showed paralysis among 1967-1970 [7]. The report emphasizes on NPEVs, including Coxsackie virus and Echovirus as major factors of AFP. This is because the clinical signs of NPEV induced AFP is similar to the poliovirus induced AFP. It is therefore important to monitor closely the reverse cold chain system of stool specimen transport, which involves maintaining a low internal temperature of the carrier boxes used in transporting stool specimens from AFP cases for the preservation of both the poliovirus and other NPEVs for isolation.

In the absence of poliovirus, NPEV isolation rates from stool samples collected from AFP cases serves as one of the global indicators in the polio eradication initiative. WHO requires that, at least $10 \%$ of stool samples submitted to the laboratory must have NPEVs isolated [8] [9] [10]. One of the key factors that could adversely affect NPEV isolation is the reverse cold chain management 
from the point of stool sample collection until it gets to the laboratory. This indicator therefore describes the condition of the stool specimen at arrival in the laboratory and determines the ability of the accredited laboratory to isolate poliovirus from that specimen if it was present.

In this study, we spotlight the country's reverse cold chain system of stool sample management from cases reported to the AFP surveillance system between 2010 and 2015. Through the distribution of their NPEV isolation rates, we identify lapses in the reverse cold chain management and provide recommendations that should help improve the reverse cold chain system and the AFP surveillance system in general as Nigeria once again matches towards a polio free certification.

\section{Methods}

\subsection{Study Design}

A descriptive retrospective study was conducted using AFP surveillance data routinely collected between January 2010 and December 2015 by the Disease Surveillance and Notification Officers (DSNOs) in Nigeria and the WHO accredited Polio Laboratories. All AFP cases reported to the Disease Surveillance network during this period from all the states were included in the study.

\subsection{Study Population}

The study population includes all children under 15 years of age that were reported by the WHO surveillance system in the country, from the $1^{\text {st }}$ of January 2010 to the $31^{\text {st }}$ of December 2015.

\subsection{Inclusion Criteria}

The onset of sudden weakness or floppiness or paralysis in children between 0 15 years of age

\subsection{Data Collection Methods}

All AFP cases reported in children less than 15 years of age were detected through active surveillance by a network of surveillance officers in all 774 LGAs of the 37 States in Nigeria.

The DSNO collected 2 stool samples at least 24 - 48 hours apart within 14 days of onset of paralysis for each case. WHO staff verifies and confirms case as a true AFP case. A true AFP case must show signs of sudden onset of weakness, floppiness or paralysis in one or more limbs of any child from zero to 15years of age. Stool sample is then transported to the laboratory for analysis. The DSNO obtained a verbal consent from parents or caregivers before stool samples were collected.

Note that information on the database was stored primarily as Microsoft Access database and Excel spreadsheet line list, with all the variables across the years in a single database. 


\subsection{Software Information}

To obtain the data used in this study, EPIINFO-a veritable customized software built by the United States Centres for Disease Control and Prevention in partnership with WHO, was used to run queries on the Access database and obtain the specific data sets required.

Specifically we ran several analysis using EPIINFO and Microsoft Excel to obtain the required data sets and produce the study results. Select-Statements command in EPIINFO was used to select the particular variable and place constraints on the time interval for the data sets needed for the study. Frequency tables were used to aggregate data by specific variables across the timelines and pivot tables on Excel was used to triangulate the datasets and sieve out the outliers before comparison tables by years were obtained.

\section{Results}

The final classification of AFP cases notified, investigated and stool specimen collected depends on the laboratory confirmation of the etiologic agent and the presence or absence of residual paralysis in cases with inadequate stool sample. In this study, a total of 52,879 AFP cases were reported from 2010-2015, in which 7288 non-polio enteroviruses were isolated.

Table 1 shows the distribution of non-polio enterovirus rate by state and geopolitical zone in Nigeria. In the south-south zone, NPEV isolation rate ranged from $9.8 \%$ in Edo to $12.9 \%$ in Cross River; while the zone cumulative rate was $11 \%$. In the south-east zone NPEV isolation rate ranged from $8.5 \%$ in Abia to $12.3 \%$ in Enugu; while the zone cumulative rate was $10.8 \%$. In south-west zone NPEV isolation rate ranged from $10.2 \%$ in Ekiti to $12.2 \%$ in Ogun; while the zone cumulative rate was $11.1 \%$. In north-central zone NPEV isolation rate ranged from $11.5 \%$ in Edo to $20.5 \%$ in Plateau; while the zone cumulative rate was $13.6 \%$. In north-east zone NPEV isolation rate ranged from 19.3\% in Gombe to $19.3 \%$ in Adamawa; while the zone cumulative rate was $20.3 \%$. In north-west zone NPEV isolation rate ranged from $10.7 \%$ in Sokoto to $20.6 \%$ in Kano; while the zone cumulative rate is $14.9 \%$.

The north-west zone recorded the highest number of AFP cases $(16,580)$ with an average NPEV isolation rate of 14.9; while the south-east zone recorded the least AFP cases (5399) with an average NPEV isolation rate of 10.8. However, the north-east zone isolated the most NPEV with an average rate of 20.3 from the 8538 AFP cases recorded in the zone; while the south-east zone isolated the least NPEV with an average rate of 10.8 from the 5399 AFP cases recorded.

On the average, the geopolitical zones in the north (north-central, north-east and north-west) recorded the most AFP cases and NPEV isolation rates (33,496 cases and 48.8 NPEV rate) in comparison to the geopolitical zones in the south (south-south, south-east and south-west) which recorded a total of 19,383 AFP cases and NPEV isolation rate of 32.9.

In the south, the south-south zone recorded the most AFP cases (8131) with 
Table 1. Distribution of Non Polio Enterovirus (NPEV) rate by state and geopolitical zone in Nigeria.

\begin{tabular}{|c|c|c|c|}
\hline Zone/State Name & Distance to laboratory (KM) & Number of AFP case Non-Polio & Enterovirus rate \\
\hline South-South zone: & & 8131 & 11.0 \\
\hline Akwa-Ibom & 676 & 1920 & 10.2 \\
\hline Bayelsa & 510 & 795 & 11.8 \\
\hline Cross-River & 772 & 861 & 12.9 \\
\hline Delta & 430 & 1500 & 10.6 \\
\hline Edo & 300 & 2083 & 9.8 \\
\hline Rivers & 656 & 972 & 11.0 \\
\hline South-East zone: & & 5399 & 10.8 \\
\hline Abia & 580 & 843 & 8.5 \\
\hline Anambra & 457 & 917 & 11.9 \\
\hline Ebonyi & 642 & 1105 & 10.8 \\
\hline Enugu & 558 & 1273 & 12.3 \\
\hline Imo & 450 & 1261 & 10.9 \\
\hline South-West: & & 5853 & 11.1 \\
\hline Ekiti & 264 & 679 & 10.2 \\
\hline Lagos & 132 & 1543 & 11.0 \\
\hline Ogun & 75 & 1096 & 12.2 \\
\hline Ondo & 204 & 972 & 10.4 \\
\hline Osun & 90 & 681 & 10.7 \\
\hline Oуо & 0 & 882 & 11.9 \\
\hline North-Central zone & & 8378 & 13.6 \\
\hline Benue & 920 & 1591 & 11.5 \\
\hline Kogi & 584 & 951 & 13.1 \\
\hline Kwara & 157 & 510 & 11.8 \\
\hline Nasarawa & 825 & 1329 & 13.6 \\
\hline Niger & 592 & 1441 & 12.2 \\
\hline Plateau & 592 & 1260 & 20.5 \\
\hline FCT & 761 & 1296 & 12.7 \\
\hline North-East & & 8538 & 20.3 \\
\hline Adamawa & 436 & 1576 & 22.2 \\
\hline Bauchi & 469 & 1842 & 18.8 \\
\hline Borno & 0 & 1293 & 21.5 \\
\hline Gombe & 400 & 1289 & 19.3 \\
\hline Taraba & 416 & 1376 & 20.2 \\
\hline Yobe & 130 & 1162 & 19.8 \\
\hline
\end{tabular}


Continued

\begin{tabular}{cccc}
\hline North-West & 16580 & 14.9 \\
Kaduna & 756 & 1798 & 14.2 \\
Kano & 574 & 4056 & 20.6 \\
Katsina & 994 & 2513 & 19.0 \\
kebbi & 679 & 3042 & 13.7 \\
Jigawa & 418 & 1527 & 10.1 \\
Sokoto & 1023 & 2033 & 10.7 \\
Zamfara & 1017 & 1611 & 15.8 \\
\hline
\end{tabular}

an average NPEV isolation rate of 11.0. The south-east zone recorded the least AFP cases (5399) with an average NPEV isolation rate of 10.8. The south-west isolated the most NPEV with an average rate of 11.1 from the 8583 AFP cases reported in the zone; while the south-east zone isolated the least NPEV with an average of 10.8 from the 5399 AFP cases reported.

On the average, the states in the south-west zone, which recorded the most NPEV isolates, are closest in terms of kilometers to the lab $(127.5 \mathrm{~km})$. The south-south which seemed farthest from lab on the average $(557.5 \mathrm{~km})$ still managed to record an average NPEV rate of 11.0 while the south-east which on the average $(447.8 \mathrm{~km})$, is closer to lab than the south-south zone states only recorded 10.8 as its average NPEV isolation rate.

In the north, the north-west zone recorded the most AFP cases $(16,580)$ with an average NPEV isolation rate of 14.9. The north-central zone recorded the least AFP cases (5378) with an average NPEV isolation rate of 15.6. The north-east isolated the most NPEV with an average rate of 20.3 from the 8538 AFP cases reported in the zone; while the north-central zone isolated the least NPEV with an average of 13.6 from the 5378 AFP cases reported.

On the average, the states in the north-east zone, which recorded the most NPEV isolates, are closest in terms of kilometers $(368.5 \mathrm{~km})$ to the lab. The north-west which seemed farthest from lab on the average $(910.1 \mathrm{~km})$ still managed to record an average NPEV rate of 14.9 while the north-central which on the average $(738.8 \mathrm{~km})$, is closer to lab than the north-west zone states only recorded 13.6 as its average NPEV isolation rate.

The WHO Polio laboratory in Ibadan serves twenty-seven states in the country; the average non-polio AFP rate among states served by this laboratory is 11.7 from a total of 4012 AFP cases recorded (Table 2).

Zamfara state recorded the most NPEV isolation rate of 15.8 from the 236 AFP cases reported while Abia state, recorded the least NPEV isolation rate of 8.5 from the 71 AFP cases reported. Meanwhile, Kebbi state reported the most AFP cases (412) with a NPEV isolation rate of 13.7 while Ekiti state reported the least (64) AFP cases with a NPEV isolation rate of 10.2.

Table 3 illustrates the distribution of NPEV isolation rate among 10 states serviced by WHO Polio laboratory in Maiduguri, the average non-polio AFP 
rate among states served by this laboratory is 19.2 from the total of 3276 AFP cases reported.

Adamawa state recorded the most NPEV isolation rate of 22.2 from the 338 AFP cases reported while Jigawa state, recorded the least NPEV isolation rate of 10.1 from the 260 AFP cases reported. Meanwhile, Kano state reported the most AFP cases (755) with a NPEV isolation rate of 20.6 while Yobe state reported the least (215) AFP cases with a NPEV isolation rate of 19.8 .

Table 2. Distribution of Non Polio Enterovirus (NPEV) rate in states served by WHO Polio Laboratory in Ibadan.

\begin{tabular}{|c|c|c|}
\hline Zone/State Name & Number of Non-Polio Enterovirus isolates & Non-Polio Enterovirus rate \\
\hline Akwa-Ibom & 197 & 10.2 \\
\hline Bayelsa & 93 & 11.8 \\
\hline Cross-River & 93 & 12.9 \\
\hline Delta & 142 & 10.6 \\
\hline Edo & 191 & 9.8 \\
\hline Rivers & 103 & 11.0 \\
\hline Abia & 71 & 8.5 \\
\hline Anambra & 105 & 11.9 \\
\hline Ebonyi & 121 & 10.8 \\
\hline Enugu & 152 & 12.3 \\
\hline Imo & 135 & 10.9 \\
\hline Ekiti & 64 & 10.2 \\
\hline Lagos & 169 & 11.0 \\
\hline Ogun & 129 & 12.2 \\
\hline Ondo & 79 & 10.4 \\
\hline Osun & 74 & 10.7 \\
\hline Oуо & 104 & 11.9 \\
\hline Benue & 167 & 11.5 \\
\hline Kogi & 122 & 13.1 \\
\hline Kwara & 59 & 11.8 \\
\hline Nasarawa & 223 & 13.6 \\
\hline Niger & 174 & 12.2 \\
\hline FCT & 155 & 12.7 \\
\hline Kaduna & 240 & 14.2 \\
\hline kebbi & 412 & 13.7 \\
\hline Sokoto & 202 & 10.7 \\
\hline Zamfara & 236 & 15.8 \\
\hline Total & 4012 & 316.4 \\
\hline Average & 148.5 & 11.7 \\
\hline
\end{tabular}


Table 3. Distribution of Non Polio Enterovirus (NPEV) rate in states served by WHO Polio Laboratory in Maiduguri.

\begin{tabular}{ccc}
\hline Zone/State Name & Number of Non-Polio Enterovirus isolates & Non-Polio Enterovirus rate \\
\hline Adamawa & 335 & 22.2 \\
Bauchi & 283 & 18.8 \\
Borno & 262 & 21.5 \\
Gombe & 238 & 19.3 \\
Taraba & 266 & 20.2 \\
Yobe & 215 & 19.8 \\
Kano & 755 & 20.6 \\
Katsina & 442 & 19.0 \\
Jigawa & 260 & 10.1 \\
Plateau & 220 & 20.5 \\
Total & 3276 & 192 \\
Average & 327.6 & 19.2 \\
\hline
\end{tabular}

\section{Discussion}

Nigeria was readmitted into the list of polio endemic countries following the detection of four WPV1 cases and one cVDPV2 case in August 2016 in Borno state, Nigeria after being polio free since July 2014 [11] [12] [13]. Though no new cases of poliovirus have been detected since August 2016 through the AFP surveillance system, it has become imperative to review various surveillance indicators of the existing AFP system for strengthening and improvement purposes as the country matches once again towards a polio free certification. This paper focuses on the reverse cold chain system of stool specimen transport from AFP cases reported to the AFP surveillance system from 2010 to 2015. Through the distribution of their NPEV isolation rates, we evaluate the strength of the reverse cold chain management, identify lapses and provide recommendations that should help improve the reverse cold chain system and the AFP surveillance system in general.

In this study, 7288 NPEVs were isolated from 52879 AFP cases reported between 2010 and 2015. This gave an average NPEV isolation rate of 13.6\% from all 6 geopolitical zones in Nigeria represented in this study. This NPEV rate is lower than the 34\% recorded in India and the 17.6\% recorded in Egypt [14] [15]. The differences in NPEV isolation rates may be attributed to poor stool collection, poor reverse cold chain and failure to adhere to standard procedures in the collection, handling and shipment of stool specimens.

Results show that the north recorded more AFP cases and isolated more NPEVs from such cases in comparison to the south. This may be attributed to the more robust and sophisticated immunization and AFP surveillance system in such parts, due to the deployment of more technical offers, resources and the presence of more partners supporting activities in north than the south. This was 
in response to the high rates of vaccine refusal once attributed to such areas of the country and high number of wild polio viruses reported [16] [17] [18]. This led to constant campaigns that are held more frequently and continuous re-education of indigenes should there be any doubts due to their religious beliefs or any other reason. This was however not the situation in the south.

The issue with proximity to the polio reference laboratories together with the reverse cold-chain system involved in the transportation of stool specimens from AFP cases, and NPEV isolation rates also come in here. This study indicates that on the average, states in the north that transported their stool specimen to the Maiduguri polio reference laboratory (north-east) isolated more NPEV in comparison to those states (mostly southern states) that transported theirs to the laboratory in Ibadan (south-west). Also, states within the same zone that were closest to the laboratories (whether Ibadan or Maiduguri laboratory) isolated more NPEVs in comparison to those that were farthest. Also, the Ibadan, which serves 27 states in the country, isolated the least NPEVs on the average in comparison to the Maiduguri, which serves the remaining 10 states in the country. It is our belief that there might be a correlation between distance to laboratory and the NPEV isolation rate. We also believe that the differences in NPEV isolation rates between both laboratories could be attributed to the number of states it served but to a lesser extent.

To this we recommend that more hands be employed in such laboratories to improve competence in work done. We also suggest that more routine checks be carried out of such laboratories to ensure that standard procedures are strictly adhered to at all times.

However, we believe that the major issue here is with the quality of the reverse cold-chain system. Notice that certain northern states (e.g. Nasarawa state: north-central, NPEV rate $=13.6$, AFP cases $=1329$ ) which reports to the Ibadan laboratory together with the southern states (e.g. Delta state, south-south, NPEV rate $=10.6$, AFP cases $=1500$ ) isolated more NPEVs even though these northern states are farthest in terms of distance to the Ibadan laboratory than the southern states reporting to the same laboratory. This indicates general lapses in the reverse cold-chain transport system particularly from the southern states.

We suggest frequent re-education of the Disease surveillance and notification officers (DSNOs) on the importance of adequate stool specimen collection, appropriate cold maintenance and insist that the DSNO personally collects one of the two stool samples collected from each AFP case. This will translate to closer monitoring of the parents/caregivers to ensure that they follow the standard guidelines for adequate stool specimen collection from their wards and boost confidence in the quality of stool specimen collected and add credibility to the collection process.

We also suggest continued provision and replacement of tools used for specimen transport such as ensuring completely availability of frozen icepacks for carrier boxes as well as the provision of a private means of transportation to curb 
any delays that may be experienced during transit, carrier boxes used for specimen transport shouldn't also be kept at the trunk of the vehicle used for transport. This is because delays and exposure to heat as a result of the carrier boxes being kept in the vehicle's trunk may affect the viral integrity. Closer monitoring of the time between stool specimen collection and commencement of transport is also recommended. If the stool cannot be transported immediately after complete collection due to time of day or travel distance, then better means of ensuring that specimen remain at the recommended condition should be put in place.

Care should also be taken when cleaning out the carrier boxes especially when using detergents. This is because these detergents could kill the enteroviruses if not thoroughly rinsed out. Alcohol, alkaline and other ingredients commonly found in detergents and soap are broad-spectrum antimicrobials. We advocate thorough rinsing with water to eliminate any residual detergent that may affect the viral integrity in the stool.

\section{Conclusion}

In conclusion, NPEV isolation rate remains a major factor for determining the quality of the AFP surveillance system. Though the country's NPEV isolation rate remains slightly higher above the $10 \%$ recommended by WHO, steps should be taken to enhance the reverse cold-chain system particularly in the southern states. This would increase confidence in the AFP surveillance system in Nigeria as she proceeds towards complete polio eradication and meeting certification standards.

\section{Acknowledgements}

The authors would like to thank surveillance field and laboratory officers for providing logistics support in data collection, patient management and non-enteroviruses isolation.

\section{Conflict of Interest}

The authors have no conflicts of interest to disclose.

\section{Author's Contributions}

$\mathrm{BEB}, \mathrm{AOE}, \mathrm{AGU}$ conducted a systematic review of the literature retrieval of data, extraction and analysis, and wrote the first draft. MST, KW, contributed to the data extraction process and also reviews the first draft. RGV, BF, BEB conceived and led the design of the study and drafting of the article.

\section{References}

[1] Alyward, R.B., Hull, H.F., Cochi, S.L., Sutter, R.W., Olive, J.M. and Melgaard, B. (2007) Disease Eradication as a Public Health Strategy: A Case Study of Poliomyelitis Eradication. Bulletin of the World Health Organization, 78, 285-297. http://www.ncib.nlm.nih.gov/pubmed/10812724 
[2] Wen, N., Fan, C.-X., Fu, J.-P., Ning, J., Ji, Y.-X., Luo, H.-M., et al. (2014) Enhanced Surveillance of Acute Flaccid Paralysis Following Importation of Wild Poliovirus in Xinjiang Uygur Autonomous Region, China. BMC Infectious Diseases, 14, 113. http://www.biomedcentral.com/1471-2334/14/113

[3] Marx, A., Glass, J.D. and Sutter, R. (2000) Differential Diagnosis of Acute Flaccid Paralysis and Its Role in Poliomyelitis Surveillance. Epidemiologic Reviews, 22, 298-316. http://www.ncbi.nlm.nih.gov/pubmed/11218380 https://doi.org/10.1093/oxfordjournals.epirev.a018041

[4] Romero, J.R. and Selvarangan, R. (2011) The Human Paechoviruses: An Overview. Advances in Pediatrics, 58, 65-85. http://www.ncbi.nlm.nih.gov/pubmed/21736976 https://doi.org/10.1016/j.yapd.2011.03.008

[5] Heim, A. (2005) From Poliovirus Surveillance to Enterovirus Surveillance: A Complete Picture? Journal of Medical Microbiology, 54, 1-2.

http://jmm.microbiologyresearch.org/content/journal/jmm/10.1099/jmm.0.45894-0 https://doi.org/10.1099/jmm.0.45894-0

[6] Assaad, F. and Cockburn, W. (1972) Four-Year Study of WHO Virus Reports on Enteroviruses Other than Poliovirus. Bulletin of the World Health Organization, 46, 329-336. http://www.ncbi.nlm.nih.gov/pubmed/4537851

[7] Landiwe, K.S., Lazarus, R.K. and Ntombenhle, J. (2013) Evaluating the Acute Flaccid Paralysis Surveillance System in South-Africa, 2005-2009-An Analysis of Secondary Data. Pan African Medical Journal, 14, 86. http://www.ncbi.nlm.nih.gov/pmc/articles/PMC3641932/

[8] Rongala, L., Prasanna, Y., Veranasi, G. and Shobha, D. (2013) Characterization of Non Polio Enterovirus Infection Associated with Acute Flaccid Paralysis in South-Western India. PLoS One, 8.

[9] Tao, Z.X., Cui, N., Liu, G.F., Chen, P., Xu, A.Q., Song, L.Z., Ji, F., Wang, H.Y. and Song, Y.Y. (2012) Complete Genome Sequence of an Enterovirus 80 Strain Isolated in China. Journal of Virology, 86, 13129-13130.

http://www.ncbi.nlm.gov/pmc/articles/PMC3497685/ https://doi.org/10.1128/JVI.02467-12

[10] Firouz, A., Tayyebeh, S. and Aida, M. (2012) Role of Non Poliovoruses in Acute Flaccid Paralysis. Journal of Gastroenterology and Hepatology Research, 1.

[11] Nathanson, N. and Kew, O. (2010) From Emergence to Eradication: The Epidemiology of Poliomyelitis Deconstructed. American Journal of Epidemiology, 172, 1213-1229. https://doi.org/10.1093/aje/kwq320

[12] WHO (2012) Parental Perceptions Surrounding Polio and Self-Reported Non-Participation in Polio Supplementary Immunization Activities in Karachi, Pakistan: A Mixed Methods Study. World Health Organization. http://www.who.int/bulletin/volumes/90/11/12-106260/en/

[13] Bassey, B.E., Rui, V.G., Gasasira, A.N., Pascal, M., Weldegbriel, G., Mulum, T.J., et al. (2014) Characteristics of Acute Flaccid Paralysis Reported by the Surveillance System and Verified by WHO Officer in Akwa Ibom State-Nigeria, 2006-2012. Health, 6, 2602-2610. http://www.scirp.org/journal/PaperInformation.aspx?PaperID=51340\&\#abstract

[14] Dievanayagam, N., Neddunchellan, K., Vasudevan, S., Ramamoorthy, N., Rathnam, S.R., Mala, N., Ashok, T.P. and Ahmed, S. (1994) Etiological Agents of Acute Poliomyelitis in South India. Indian Journal of Pediatrics, 61, 257-262. http://www.ncbi.nlm.nih.gov/pubmed/7959999

[15] Salwa, A., Samar, A.Z., Aly, F.M. and Hend, H. (2009) Isolation and Identification 
of Non-Polio Enteroviruses from Children in Different Egyptian Governorates. Australian Journal of Basic and Applied Sciences, 3, 3230-3238.

http://www.researchgate.net/publication/228782406_Isolation_and_Identification_ of_Non-Polio_Enteroviruses_from_Children_in_Different_Eqyptian_Governorates

[16] Jegede, A. (2007) What Led to the Nigerian Boycott of the Polio Vaccination Campaign? PLOS Medicine, 4, e73. https://doi.org/10.1371/journal.pmed.0040073

[17] Dhole, T.N., Ayyagari, A., Chowdhary, R., Shakya, A.K., Shrivastav, N., Datta, T. and Prakask, V. (2009) Non-Polio Enteroviruses in Acute Flaccid Paralysis Children of India: Vital Assessment before Polio Eradication. Journal of Paediatrics and Child Health, 45, 409-413. http://www.ncbi.nlm.nih.gov/pubmed/19712176

[18] Dietz, V., Andrus, J., Olive, J.M., Cochi, S. and de Quadros, C. (1995) Epidemiology and Clinical Characteristics of Acute Flaccid Paralysis Associated with Non Polio Enterovirus Isolation: The Experience in the Americas. Bulletin of the World Health Organization, 73, 597-603. 